\title{
Lexis
}

Journal in English Lexicology

$4 \mid 2010$

Corpus Linguistics and the Lexicon

\section{Meaning Extensions of Grasp: A Corpus-Based Study}

Marie Nordlund

\section{OpenEdition}

Journals

\section{Electronic version}

URL: http://journals.openedition.org/lexis/603

DOI: 10.4000/lexis.603

ISSN: 1951-6215

\section{Publisher}

Université Jean Moulin - Lyon 3

\section{Electronic reference}

Marie Nordlund, « Meaning Extensions of Grasp: A Corpus-Based Study », Lexis [Online], 4 | 2010,

Online since 14 April 2010, connection on 05 May 2019. URL : http://journals.openedition.org/

lexis/603 ; DOl : 10.4000/lexis.603

\section{(@) $\Theta \Theta$}

Lexis is licensed under a Creative Commons Attribution-NonCommercial-NoDerivatives 4.0

International License. 


\title{
Meaning Extensions of Grasp: A Corpus-Based Study
}

Marie Nordlund ${ }^{1}$

\begin{abstract}
By means of a lexico-semantic analysis, the aim of this paper is to provide a clearer picture of how the English verb grasp is used in actual language production. The material for the analysis has been gathered from the 100 million word British National Corpus. The results of the study provide new and valuable information about the character and use of the verb and thereby supplement the information about grasp already existing.
\end{abstract}

Keywords: meaning extension - word meaning - conceptual mapping - cognitive linguistics - corpus linguistics - usage-based - lexicology - semantics - verb analysis

$$
* * *
$$

\section{Résumé}

L'objectif de cette étude est de donner une image plus précise de la façon dont le verbe anglais grasp est employé en discours. L'analyse lexico-sémantique utilise le British National Corpus, corpus de 100 millions de mots. Elle donne des informations inédites et importantes sur le caractère et l'usage du verbe, qui expliquent et complètent l'information disponible.

Mots-clés : élargissement du sens - sens du mot - mapping conceptuel - linguistique cognitive - linguistique de corpus - basé sur l'usage - lexicologie - sémantique - analyse de verbe

\footnotetext{
${ }^{1}$ Department of Languages and Culture, Luleå University of Technology (Sweden): Marie.Nordlund@1tu.se
} 


\section{Introduction}

Verbs are especially interesting when it comes to the study of word meanings because they are "arguably the most important lexical and syntactic category of a language [...] provid[ing] the relational and semantic framework for [the] sentence" [Fellbaum 1990: 278]. Since speakers have a lot of complex syntactic and semantic information about verbs stored in their mental lexicons, Fellbaum [1990: 278] claims that this is the lexical category which is the most difficult to study. Pickering and Frisson are of the same opinion and declare that "in English, verbs are psychologically more complex and therefore more difficult to process than nouns" [2001: 557]. The difficulties are further enhanced by the polysemous nature of many verbs. According to Fellbaum [1990: 278], verbs have on average 2.11 usages as compared to 1.74 for nouns. In part, this is so because "a noun typically forces a collocate adjective, verb, or preposition to adjust its meaning so that it becomes compatible with that of the noun" [Alm-Arvius 2007: 50]. Pickering and Frisson [2001: 557] note that in interpretations, verbs are more "malleable" than nouns and therefore more central to the semantic cohesiveness of a sentence. Thus, whereas the meaning of a noun is relatively stable no matter which verb it cooccurs with, a verb is more likely to have its meaning affected by the presence of a certain noun.

The importance of studying language actually produced by people is emphasised by, for example, Sinclair who states that "human intuition about language is highly specific, and not at all a good guide to what actually happens when the same people actually use the language" [1991: 4]. Kemmer and Barlow [2000: xv] stress the importance of usage-based analyses, that is, analyses of data retrieved from corpora, and maintain that the linguist's primary object of study should be language in use. Using corpus data for linguistic analyses has several advantages compared to other approaches, such as the use of elicited or introspective data. Gries and Divjak list the following advantages:

- corpora provide many instances rather than a few isolated judgments

- corpora provide data from natural settings rather than 'armchair' judgments or responses that potentially reflect experimentally-induced biases

- corpora provide co-occurrence data of many different kinds

- corpora allow for bottom-up identification of relevant distinctions as well as for a more comprehensive description than is typically provided

[Gries \& Divjak 2009: 60]

Corpora have become important tools for linguistic analysis. The approach adopted here is thus in line with the most recent developments within the field.

\subsection{Aim and scope}

By means of a lexico-semantic analysis, the aim of this paper is to provide a clearer picture of how the English verb grasp is used in actual language production. Specific questions that are addressed are:

- To what extent is the verb used as a mental verb?

- What other usages ${ }^{2}$ does the verb display?

\footnotetext{
${ }^{2}$ The analysis does not address the issue of homonymy versus polysemy, that is, whether grasp should be seen as a homonymous word with distinct meanings rather than as a polysemous word with distinct senses. Therefore, in preference to the terms meaning and sense, which are often used in linguistics to describe
} 
- What is the relative frequency of different usages for the verb?

In answering these questions, the current work adds new and valuable information about the character and use of grasp. It has been noted [Hanks 1996: 80] that the imbalance between different usages of a word, which is clearly noticeable in a corpus analysis, is not mentioned in dictionaries where the rarest usage is given the same weight as the most frequent one. Furthermore, in their study of crawl Fillmore and Atkins [2000: 95] find that many of the frequently occurring usages found in the corpus do not have a corresponding definition in any of the six dictionaries surveyed. Observations in line with those recorded by Hanks and by Fillmore and Atkins are made in the research presented here as well. The analysis of the data thereby supplements the information about the verb already existing.

\subsection{Method and material}

To establish how the verb is used the British National Corpus (BNC) was searched. This corpus, which was compiled between 1991 and 1994, is one of the largest language corpora presently available to the general public, containing approximately 100 million words, from both spoken (10\%) and written (90\%) British English, the latter representing a wide variety of text genres. The BNC is surpassed in size only by Collins Cobuild's Bank of English currently containing 524 million words and the recently launched 360 million word BYU Corpus of American English. The advantage of using the BNC is that it is fixed and stable. It is thus possible to search for and retrieve exactly the same material even after a lapse of several years. Still, not even a corpus of the size of the BNC can be exhaustive. It only represents the language produced during a specific period of time and it might be biased towards one specific register. In the case of the BNC, for example, it is possible that the predominance of written language in the corpus may influence the results achieved. As observed by Roland and Jurafsky [1998, 2002], there is much variation between corpora as regards the frequencies of usages as well as which usages are found. It should also be remembered that even if a corpus does not contain any evidence of, for example, a certain verb usage, this can only be taken as an indication that the usage is rare, not as proof that it does not exist. Bearing these limitations in mind, using the BNC nevertheless provides a comprehensive and varied working material.

The data retrieved from the BNC is analysed as regards different usages as well as regards the semantic roles that occur together with the verb. Semantic roles are a complex matter and the analysis reveals that the various usages of the verb demand a variety of semantic roles to correctly label the participants. A full specification of all the semantic roles encountered in the analysis would be detrimental to a clear overview of the results. Therefore, the terms grasper and graspee are used throughout the analysis to facilitate presentation and discussion of the results. The term grasper refers to the noun phrases constituting the syntactic subjects of active sentences as well as agents of passive sentences, whereas graspee refers to all the clause elements that are directly affected by the action expressed by the verb. These elements are most commonly the direct objects of active sentences and the syntactic subjects of passive sentences. The two terms are thus used as shorthand to cover all the major semantic roles in which these clause elements can appear depending on in what way they are semantically involved in the action, process, state or event denoted by the verb. The survey of graspers and graspees is made because the interpretation of a verb is to a very large extent dependent on its arguments. This is also the outcome of psycholinguistic experiments on the interpretation of polysemous verbs [Gibbs \& Matlock 1999]. Direct objects, in particular, are generally of

homonymy and polysemy respectively [Klein \& Murphy 2001: 259], and following Sandra and Rice [1995], the more neutral term usage will be used in the analysis to denote the different ways in which grasp can be interpreted. 
decisive importance for how a verb is interpreted [Ide \& Véronis 1998: 20; Pickering \& Frisson 2001: 557]. Furthermore, an analysis of the graspees could also reveal semantic patterns that might otherwise remain undetected.

In the analysis, frequencies for verb usages as well as for graspers and graspees are presented in the form of tables comprising main categories and subcategories. The basic criteria used to identify the different categories were whether or not a concrete action was described and, if not, whether or not the verb was used within the mental domain. The nature of the graspee was of decisive importance in assigning instances of the verb to one category or the other. For verb usages, this resulted in the three main categories physical, non-physical (other than mental) and mental usages. To establish the earliest attested records for each of these main categories the Oxford English Dictionary (OED) was consulted. In the presentation of example sentences the original source is referred to in the following order: author, title, year of publication and genre. The genres are the ones used in the BNC and they are here referred to with the abbreviations SP (= spoken language), AC (= academic writing), NEWS (= newspaper article), FIC (= fiction) and MISC (= miscellaneous other categories of written language).

\section{Grasp}

The data shows that physical grasping is strongly associated with the use of hands or fingers. Furthermore, grasp is the textbook example of how physical verbs extend into the mental domain. The analysis shows that the verb is used within the mental domain to a great extent. Mental usages are predominant in the data and account for almost half of the material. The results of the analysis further demonstrate that in certain contexts the interpretation of grasp differs quite considerably from the definitions usually provided in dictionaries.

\subsection{Grasp in the OED}

The earliest attested record in the OED for each of the main usage groups physical, nonphysical and mental grasping is:

PHYSICAL: $\quad$ to make clutches with the hand (1382)

NON-PHYSICAL: to seize and hold firmly with the hand (figurative or in immaterial sense) (1602)

MENTAL: to lay hold of with the mind; to become completely cognizant of or acquainted with; to comprehend (1680)

There are thus attested instances of physical usages a little more than two hundred years earlier than for any non-physical usage. Extended usages of grasp as a mental verb are first attested approximately one hundred years later.

\subsection{Grasp in the $B N C$}

\subsubsection{Usages of grasp}

The material retrieved from the BNC contains 1,505 instances of grasp, grasps, grasping and grasped. The analysis shows that grasp is a verb of instantaneity. The usages attested in 
the data are more or less variations on the same theme: one clutches at, seizes or holds firmly with one's hands, fingers or arms. The only exception to this is, of course, mental grasping where one's mind is used instead of one's hands. However, the analysis of the data retrieved from the BNC shows that there are more aspects of grasp than these. Table 1 presents the distribution of the different usages of grasp found in the corpus.

\begin{tabular}{|c|c|c|c|c|}
\hline Usage & \multicolumn{2}{|c|}{ Number of tokens } & \multicolumn{2}{|c|}{ Percentage } \\
\hline Physical grasping & & 558 & & 37.08 \\
\hline $\begin{array}{l}\text { - grasp and hold (concrete } \\
\text { entity) }\end{array}$ & 558 & & 37.08 & \\
\hline $\begin{array}{l}\text { Non-physical grasping (other } \\
\text { than mental) }\end{array}$ & & 223 & & 14.82 \\
\hline $\begin{array}{l}\text { - grasp and hold (abstract } \\
\text { entity) }\end{array}$ & 209 & & 13.89 & \\
\hline - miscellaneous usages & 14 & & 0.93 & \\
\hline Mental grasping & & 724 & & 48.10 \\
\hline - understand & 688 & & 45.71 & \\
\hline - learn & 19 & & 1.26 & \\
\hline - accept & 6 & & 0.40 & \\
\hline - perceive & 6 & & 0.40 & \\
\hline - miscellaneous usages & 5 & & 0.33 & \\
\hline Total & & 1,505 & & 100.00 \\
\hline
\end{tabular}

Table 1. Usages of grasp

\subsubsection{Physical grasping}

Even though physical grasping of a concrete entity emerged much earlier than any other usage, it is not the one with the greatest number of occurrences in the data: physical grasping accounts for no more than 558 examples (a little more than $37 \%$ of the material as a whole). One reason why physical grasping appears relatively rarely could be that grasp in physical usages has to compete with other verbs that can be used in similar contexts, for example, take hold of, seize, grab and grip. Interpreted as 'grasp and hold', grip is almost twice as frequent as grasp in the BNC, whereas grab is four times as common. Take hold of and seize occur slightly less frequently. ${ }^{3}$ In sentences with mental grasping, on the other hand, grasp cannot be as easily substituted by another verb, except for understand.

The analysis of grasp indicates that there are aspects of the physical act that are part of non-physical usages as well. 'Grasp and hold' seems to be a potential candidate for a core feature central to the semantics of grasp. Biber, Johansson, Leech, Conrad and Finegan [1999: 361] observe that for verbs with more than one usage it sometimes happens that the verb more commonly appears in usages lacking such a central feature. They refer to this as "as non-core sense" [1999: 361] which people tend not to mention first when asked to define a word. In his study of the abstract noun time, Evans [2004] comes to the conclusion that the word's different usages are organised around "a sanctioning sense" [2004: 80] that typically is close in meaning to the earliest recorded usage. It is also the usage that language users are most likely to name if asked to give a definition of time. He points out, however, that this does not necessarily mean that the sanctioning sense is the most frequent one [Evans 2004:

\footnotetext{
${ }^{3}$ The figures are based on a search of a subpart of the BNC, the A- and C-files, which represent approximately one-third of the corpus.
} 
261, fn. 2]. Future informant testing is likely to show whether 'grasp and hold' really constitutes a central feature of the semantics of grasp.

The examples of physical grasping are all concerned with grasping with one's hands, fingers or arms (or with a body part of an animal used in the same way) and holding the entity in a firm grasp, as exemplified in sentences (1) and (2):

(1) Its end is both sticky and muscular so that a toad can use it first to grasp a worm or a slug and then to carry it bodily back to the mouth. [Attenborough, D., Life on earth, 1988, MISC]

(2) Suddenly she was grasped from behind and the sky swam all around her $[\ldots]$ [Fox, N., Love or nothing, 1993, FIC]

Most commonly, the body part used is the hands: almost $90 \%$ of the instances referring to physical grasping involve the use of hands. In the BNC, physical grasping always relates to an instantaneous action, to a situation describing temporary acquisition: there is no intention of keeping the entity grasped, only to establish an amount of control. This is characteristic of what Levin [1993] calls 'hold verbs', a category in which she includes grasp. Hold verbs "describe prolonged contact with an entity, but they do not describe a change of possession or a change of location" [Levin 1993: 145]. The grasper grasps someone or something and only retains her or his hold for a (usually) short period of time.

\subsubsection{Non-physical grasping other than mental}

Non-physical grasping accounts for just below $15 \%$ of the data and is thus the least frequent usage group. It is here exemplified by sentence (3):

(3) $[\ldots]$ and it will marvel at the failure of countries and their leaders to grasp the opportunities for progress. [Hansard extracts 1991-1992, MISC]

Most examples with an abstract entity as the graspee involve the grasping of an opportunity and the like, as exemplified by (3). There are seventy examples of this sort and the phrase grasp the opportunity/chance could thus be regarded as a fairly common collocation. This fact is also acknowledged in many dictionaries where the phrase is often included under the entry of grasp. Using an opportunity for one's own benefit usually means acting quickly since the chance might not be repeated. The collocation is motivated by the instantaneous character of grasp.

The data on non-physical grasping also contains examples of idiomatic expressions. The vast majority (sixty tokens) involves the idiom to grasp the nettle 'to deal with a difficulty in a decisive way':

(4) The Government has shown in the past that it is willing to grasp nettles that others have shied away from, [...] [The Independent, electronic edition of 5 October 1989, NEWS]

What kind of "nettle" is to be grasped is sometimes specified attributively, the legal nettle, the management nettle, and sometimes in a following of-construction, the nettle of recession, the nettle of a common agricultural policy. There are examples in the data that indicate that there appears to be some confusion among language users as to the construction of this idiom, as illustrated in sentence (5): 
(5) We all would, but the question is is John Major the man to grasp that mettle? [Bill Heine radio phone-in, date unknown, SP]

It seems here as if the two idioms to grasp the nettle and to show/prove one's mettle have been mixed. This is probably due to the similarities in spelling and pronunciation of nettle and mettle and also to the similarity between the meanings of the idioms, 'to deal with a difficulty in a decisive way' and 'to show that one has the ability to deal with a difficult situation', respectively. ${ }^{4}$

The usages of grasp discussed so far can all be regarded as rather conventionalised, that is, they are entrenched in the minds of language users and thereby cognitively routinised. There are, however, examples in the data where the context indicates that grasp must be given an interpretation that differs quite substantially from those mentioned above. Still, these examples retain traces of the physical act and the extensions from a physical usage are in that way motivated. In some of the examples, it is possible to interpret grasp as 'comprise', or possibly as 'catch':

(6) $[\ldots]$ because public choice theory narrowly defines bureaucratic behaviour in terms of budget or staff maximization, it fails to grasp more important aspects of bureaucratic rationality - such as the desire to avoid conflict from troublesome staff at lower levels and interference from councillors. [Andersson, J. \& A. Cochrane (Eds.), Politics in transition, 1989, AC]

Depending on the context, physical grasping can be interpreted as 'embrace', that is, grasping and encircling with one's arms. Sentence (6) can be seen as an example of an extension from this usage, an extension that is motivated by the perceived similarity between a human grasper embracing someone/something so as to almost make them/it a part of her-/himself and an abstract grasper comprising something, where indeed the graspee is made part of the grasper. An interpretation within the mental domain would not possible, however, due to the abstract nature of the grasper, tpublic choice theory.

There are other examples where the context suggests that the closest interpretation of grasp is 'describe':

(7) Yet, despite this intimacy, the fact that they exist as a couple with a unique value in each other's eyes (a point marvellously grasped in Donne's love-poetry), they remain separate, even when man and woman strive to overcome the fundamental dualism of life. [Vickers, B., Returning to Shakespeare, 1989, AC]

Here, too, the non-physical use of grasp must be regarded as an extension from physical grasping. The verb capture is probably a more established metaphor for describe than grasp. ${ }^{5}$ In sentences such as (7), the use of grasp might be explained by the semantic similarities that exist between grasp and capture.

Yet another possible interpretation of grasp is illustrated in (8):

\footnotetext{
${ }^{4}$ It could be discussed whether or not the use of mettle is due to a simple typographic error. However, discussions of the correctness of grasp the nettle versus grasp the mettle on several websites (see, e.g. www.phrases.org.uk, www.mumsnet.com and www.worldwidewords.org) suggest that language users actually are confused about which construction is correct.

${ }^{5}$ See, for example, the definitions of capture in the LDOCE and Macmillan.
} 
(8) Hygienists spoke of the need to grasp the actual moment when the nerve centres of life were poisoned through hereditary influence or degenerate living.

[Mort, F., Dangerous sexualities, 1987, AC]

In this example, the verb can be interpreted as 'pinpoint' and it is still possible to see the connection with physical grasping that has motivated the extended use of grasp.

The usages of grasp illustrated by examples (6) through to (8) may seem to be somewhat peripheral with respect to a central semantic feature of the verb. It is, however, possible to motivate their presence among the usages of grasp because they are all in one way or another related to physical grasping. In the same vein as Wittgenstein [1953] formulated his theory of family resemblances within noun categories, the philosopher John Austin [Lakoff 1987: 18] thought of word usages as forming a category, similar to that described by Wittgenstein, around a primary nuclear usage. According to this view, the different usages can be said to constitute a category not because they share properties but because they are related to each other in specifiable ways. In other words, elements of the situations depicted in examples (6) through to (8) have been seen as somehow related to elements of physical grasping and those relationships motivate the extended use of grasp. Still, there is a strong possibility that these usages cannot be said to be distinctly separated in the minds of language users, that is, as conventionalised. They are rather to be regarded as variations dependent on context and background knowledge for their interpretation [see, e.g., Tyler \& Evans 2003]. It could be argued that because grasp displays such a wide range of non-physical usages, mental usages included (see also 2.2.1.3 below), and incorporates so many different extensions from the physical act, it should be considered a complicated verb [cf. Pickering \& Frisson 2001: 557] with many facets that need to be taken into account. It is more probable, however, that grasp as such can be regarded as semantically quite simple and that it is this simplicity that makes the many extensions possible. From this perspective, the different usages can be seen as forming a network of usages emanating from the verb's suggested central feature.

In the data there are another four cases where the use of grasp is more puzzling. In example (9) the expression grasp the point has been used:

(9) Trying to imagine Suede on Top Of The Pops, one pictures a mint conditionMorris Minor Traveller (with the wooden bits on the window frames) in a stock car race comprised of BMW 320s or some other Yuppie-scum-sucking vehicle of that nature. That doesn't really grasp the point, but it sets Bernard off on another low-fi tirade against "jump up and down bands" becoming part of the mainstream and generally bringing the whole world down: [...] [New Musical Express, 1992, MISC]

Usually, this phrase means 'understand', but the context does not support such an interpretation. Rather, it seems here that what the writer wants to express is that a problem has not been approached, described or illustrated in the right way. The use of this particular phrase in the context of (9) might be due to a simple mix-up or possibly the result of a specific jargon. In example (10) another fixed phrase has been used, grasp the situation:

(10) [The Holy Spirit] knows the varied and perplexing circumstances in which we are placed. And he helps - the very word in Greek is highly suggestive. It means he grasps the situation for us and with us. He frames the petitions in our lips; and he prays within us to the Father, with sighs too deep for words. [Green, M., I believe in the Holy Spirit, 1985, MISC] 
Apart from (10), there are other examples in the material containing the same phrase where the meaning of the expression is 'understand the situation', for instance:

(11) It looks as if Mr Honecker, 77 and only slowly recovering from a gallbladder operation, is incapable of grasping the situation in his country. [The Independent, electronic edition of 4 October 1989, NEWS]

In (10), however, this interpretation does not seem to be applicable. Instead, the context suggests that the grasping of the situation in this case has more to do with making something happen than with understanding something. It is also possible that the use of grasp in (10) is no more than an instance of the verb being used in the wrong way, that is, an involuntary error on the part of the writer.

Sentence (12) contains the expression grasp an appreciation, which at first sight does not seem to make sense: ${ }^{6}$

(12) The song is but brief, and perhaps an appreciation of Kerman's penetrating, if occasionally purple, dissection and minute analysis would have been much easier to grasp had all the music been reproduced. [Early Music, 1993, AC]

A Google search, however, resulted in 749 hits for grasp/grasping/grasped an appreciation, predominantly on American web-sites. ${ }^{7}$ Considering the examples found, the expression appears to have two different interpretations, 'understand' and 'appreciate, value', the latter of which seems to be the most appropriate in the context of (12).

Finally, example (13):

(13) I am one of many who saw the appointment of Dr Carey as Archbishop of Canterbury as a prophetic choice for England. I only pray that the vision which he grasped so clearly for the local church might be taught clearly and then caught by the whole Church of England. [Cleverly, C., Church planting: our future hope, 1991, MISC]

Here, the use of grasp might be a case of mental grasping, that is, 'understand' (see 2.2.1.3 below), but it looks as if the context calls for a more complex interpretation consisting of more than one layer, where the vision is first interpreted, pondered over and adopted by $\mathrm{Dr}$ Carey who then introduces it to the local church where it is implemented. Again, this is an expression that does not appear to make sense, but there are actually between two and three hundred instances of different forms of grasp a/the vision for on the Internet. ${ }^{8}$

\subsubsection{Mental grasping}

Mental grasping constitutes the largest part of the data analysed on grasp (about 48\%) and the most frequent usage is 'understand'. The earliest attested example of this usage, according to the OED, appeared approximately three hundred years later than the original act of physical grasping. Conceptual mappings from physical or perceptual domains to mental ones are frequent in many languages [see, e.g., Sweetser 1984, 1987, 1990]. Within cognitive linguistics the human body and its functions are seen as providing a frame for humans to conceptualise and organise the world around them [e.g. Johnson 1987]. Hence, it is a fairly

\footnotetext{
${ }^{6}$ Discussions with native speakers of British English also confirm this.

${ }^{7}$ The search was carried out on 13 February 2007.

${ }^{8}$ A Google search was conducted on 28 April 2008.
} 
small step from accessing something by physically grasping it with one's hands to getting mental access to something by grasping it with one's brain, that is, understanding it. In this instance, then, the development of grasp over the centuries can be regarded as a natural process, linguistically and conceptually. It is also likely that a high degree of entrenchment [Langacker 1987] could speed up the process of semantic change. In other words, a possible development is that because grasp is used so often as a mental verb the result could be that it will be used even more within the mental domain. In total, there are 688 examples (or just below $46 \%$ of the data as a whole) of the usage 'understand', for instance:

(14) $[\ldots]$ Grundy, the modest television company that never really grasped Neighbours worldwide success. [Stone, S., Kylie Minogue: the superstar next door, 1989, MISC]

(15) $[\ldots]$ it was easy to grasp that the changes they foreshadowed would be fundamental. [Pluckrose, H., What is happening in our primary schools, 1987, $\mathrm{AC}]$

Usually, the grasper is human and organisations ${ }^{9}$ appear in that role, too, as shown in (14), but there are also a few examples involving animals as graspers in sentences where grasp can be interpreted as 'understand':

(16) Horses are not stupid and will soon grasp how to avoid hard graft! [Today's Horse, 1991, MISC]

(17) Were a chimp to grasp the meaning of "in" or "on" in Ameslan [...] [Minds, machines and evolution, 1987, AC]

Hence, it does not seem to be the case that a human grasper is necessary for grasp to be used in this extended way. However, the examples found in the corpus involve animals which are usually regarded as quite intelligent, as explicitly stated in (16). Even though the data is not extensive enough to draw any definite conclusions, it therefore seems as if intelligence were a prerequisite for the usage 'understand' to be extended into the animal realm. In the case of the chimp in (17), its ability to use its hands in the same way as a human is a further motivation for this extended use of grasp.

In addition to cases where grasp is interpreted as 'understand', there are examples with similar but not exactly the same meaning, as illustrated by the following:

(18) Corbett nodded understandingly while he concentrated on listing a sequence of events surrounding the Scottish King's death. There was something wrong, very wrong but he could not grasp it. [Doherly, P.C., Crown in darkness, 1991, FIC]

In this example, grasp can of course be interpreted as 'understand', but equally well as 'put one's finger on'. The choice of one interpretation instead of the other appears to be one of nuance. Sentences (19) and (20) exemplify similarity of meaning of another kind. Here, a plausible interpretation of grasp seems to be close to 'memorise'.

(19) [...] but all the while she was watching him, seeing how his eyes cast a line to the climbing bird. Saw how he grasped every last detail of it and held that

\footnotetext{
${ }^{9}$ Organisation is used as a cover term for named companies as well as for countries and their institutions.
} 
knowledge tight in his memory. [Wingrove, D., Chung Kuo book one: the Middle Kingdom, 1989, FIC]

(20) To this, as he matured, more was added, until the whole declaration of faith was perfectly grasped, part of his deepest consciousness: [...] [Doman, L.S. \& C. Rawlins, Leonard Cohen: prophet of the heart, 1990, MISC]

Mental usages of grasp often seem to overlap, which often makes a definite categorisation impossible. This is illustrated in sentence (20) where it would be possible to interpret the meaning of grasp as 'learn' or 'understand' as well. Again, this is a case where it is difficult to decide on one single interpretation. Another detail worth noting here is how conceptual metaphors such as IDEAS ARE OBJECTS [e.g. Lakoff \& Johnson [1980] 2003], UNDERSTANDING AN IDEA IS ESTABLISHING PHYSICAL CLOSENESS [Jäkel 1995: 199], THE MIND IS A BODY [Sweetser 1990; Lakoff \& Johnson 1999] and THE MIND IS A CONTAINER [Gibbs 1994: 162] are given expression in (19): every detail is grasped and that knowledge is held tight in memory.

In the same way as a physical entity can be shelved and later brought out when needed, it should be possible to access knowledge again once it has been stored in memory.

(21) He tried to grasp what he had been rehearsing but he seemed to have lost it. [Joseph, J., Persephone, 1986, FIC]

Sentence (21), in which grasp is best interpreted as 'retrieve', shows that it is not always the case that it is possible to recall pieces of knowledge. Just as it sometimes happens that physical entities are mislaid, things once learned may also be lost, that is, forgotten.

In addition to sentence (20) above, there are other sentences where it could be argued that grasp should be interpreted as 'learn'. Sentences (22) and (23) are examples of this:

(22) The general lesson to be grasped from these observations is clear. [Barnett, R., The idea of higher education, 1990, AC]

(23) Academic basics can be drummed into a reasonably receptive dealer through the BIDS or Stock Exchange courses, but the practical market know-how that was most needed could be grasped only over a period. [Davidson, A., The City share pushers, 1989, MISC]

Since lexemes such as lesson and know-how belong to the domains of knowledge and learning, the contexts in these two examples also make the interpretation of grasp as 'learn' plausible. The difference between learning and understanding is a minor one and the two concepts are intimately intertwined: learning something generally includes understanding it and vice versa. The following sentences exemplify contexts where grasp can be interpreted as either 'understand' or 'learn':

(24) Far from being an enriching process in which students can more easily grasp the basics of science, [...] [Royal Society of Chemistry, Chemistry in Britain, 1992, MISC]

(25) Provide some evidence that the function of paragraphing (ie to separate distinct ideas, events, etc and to unify related ones) has been grasped. 
[Department of Education \& Science, National curriculum English (ages 5-16), 1989, MISC]

Again, because of the close relationship between understanding and learning, as regards these and other sentences of the same kind, it is difficult, and perhaps not necessary, to decide on only one interpretation of grasp. Fuzzy edges and overlap between usages are common features of language.

Other examples involve grasp expressing 'acceptance', which is exemplified by sentences (26) through to (28):

(26) [... the great truth] which the Church still finds so hard to grasp, namely that God does indeed throw his largesse to all and sundry. [Dennis, T., Lo and behold!, 1991, MISC]

(27) Howard is still a little jealous of his authority, hasn't yet quite grasped the new set-up since my Ministry was established. [Forbes, C., Shockwave, 1990, FIC]

(28) I should hate him, only it seems so unreal sometimes, as though none of it ever happened. I know it did, but sometimes I can't grasp the reality. [Richmond, E., A stranger's trust, 1991, FIC]

To a great extent, 'accept' and 'understand' are concepts to which the same mental processes are applied. Hence, the boundary between them is very fine. Considering the contexts, however, especially in (26) and (27), it seems as if the acceptance involves a certain amount of reluctance.

There are also a small number of sentences in the data where it appears to be possible to interpret grasp as some kind of perception, as is illustrated by sentence (29):

(29) An audience listens to music, not to words (in fact, especially in choral music, the words are frequently indistinguishable, or so difficult to grasp that listeners ignore them). [Brindle Smith, R., Musical composition, 1986, AC]

In the sentence above, a plausible interpretation of grasp is 'hear' or 'discern'. Other examples include visual and tactile perception. It could perhaps be argued that mental grasping is not the best categorisation for such examples. The decision is motivated by the fact that both perception and understanding are cognitive faculties and the former usually leads to the latter. According to the modality hierarchy proposed by Viberg [1984: 136], the path for semantic extensions of sense modalities commonly go from sight and hearing to touch, whereas sentence (29) seems to indicate an extension in the reverse direction. It is very likely, however, that examples such as (29) are isolated off-the-cuff cases. For all the various mental usages of grasp discussed here, the situation is the same as for the extended nonphysical usages in that they are highly dependent on the surrounding context for their interpretation.

In addition to the extension from physical grasping performed with one's hands to mental grasping performed with one's brain, there are two examples where an image of physical grasping is used to further enhance the extended usage of 'understand'.

(30) Every solid fact slipped out of Blanche's grasp as soon as she believed she grasped it. [Barnes, T., A midsummer killing, 1991, FIC] 
(31) No one fully understands the workings of these interlocking systems and we may forgive ourselves for having a sensation of something slipping through our fingers when we try to grasp them [...] [Cook, G., Discourse, 1992, MISC]

Here, the phrases slipped out of Blanche's grasp in (30) and slipping through our fingers in (31), both instances of physical grasping, are used in combination with grasp as a mental verb. This clearly shows how the physical action of grasping something with one's hands has been extended to the mental action of grasping something with one's brain, that is, understanding it. Again, the examples in (30) and (31) can be seen as motivated by the IDEAS ARE OBJECTS metaphor [Lakoff \& Johnson [1980] 2003]. This is further enhanced by the description of the facts in (31) as 'solid'. It is also worth noting that grasp as 'understand' often co-occurs with other words from the same semantic domain, for example, understand, know, comprehend, learn, memory and knowledge, as illustrated by (31) above and by the following sentences:

(32) And if we can learn more about their sensitivity to ultrasonic sounds, we may finally grasp how they can "know" that someone is approaching from a great distance. [Morris, D., Catlore, 1989, MISC]

(33) $[. .$.$] form allows a sense of completeness in a work of art, one that can be$ grasped by us and held in our memories. [Brindle Smith, R., Musical composition, 1986, AC]

In total, 724 examples (a little more than $48 \%$ ) of various forms of mental grasping have been found in the corpus material.

In addition to the issues presented so far, the data provides yet another detail worth pointing out. When grasp is used for mental grasping the statements are often negative or express an amount of uncertainty: almost $39 \%$ of the examples of mental grasping contain such features, here exemplified by sentence (34).

(34) And being engrossed in our present moments, we fail to grasp the significance of the time behind and the time ahead. [Davidson, J., Natural creation \& the formative mind, 1991, MISC]

This can be compared with physical grasping where the corresponding figure does not reach $3 \%$ and other kinds of non-physical grasping with a figure just below $17 \%$. Of course, this might be just a coincidence, a quirk in the corpus, but since the differences are quite considerable another explanation must be looked for. Unfortunately, the data available does not provide enough information for anything but guesses. It may be the case that physical grasping, an act which is quite simple and as such does not involve much effort, is considered more likely to reach a successful conclusion than is mental grasping. When grasping for an entity one usually ends up having it in one's hands. When one tries to understand something, on the other hand, it is not always the case that one succeeds and, in addition, the process of understanding often requires a certain amount of effort. This is also observed by Vanparys [1995: 22] who claims that grasp implies that the hearer might experience difficulties when trying to understand an utterance. Moreover, a connection between grasp and the understanding of difficult issues is sometimes mentioned in dictionaries as in, for example, the LDOCE where one definition of the verb is 'to completely understand a fact or an idea, especially a complicated one' (emphasis added). Taking into account the number of 
statements with grasp expressing negation or uncertainty, it seems as if Vanparys' claim might hold true. However, the example sentence used by Vanparys (I grasped the main points of the speech), retrieved from his main data source the LDOCE, does not show convincingly enough that any difficulties in understanding are implied by the verb. Rather, implicatures of that sort, if any, appear to derive from the context, which supports a view that context has a major influence on the interpretation of words and sentences [see, e.g., Ide \& Véronis 1998; Kemmer \& Barlow 2000; Klein \& Murphy 2001, 2002]. In order to obtain more data for comparison, the BNC A-files, which contain about 14.6 million words, were search for instances of the verb understand. It turned out that $38 \%$ of the sentences with understand express either an inability to understand on behalf of the hearer or a degree of uncertainty concerning whether an understanding really has been reached. This figure corresponds very well with that for mental grasp (close to 39\%) and could, thus, be taken as further evidence that the difficulties hearers might experience when they try to make sense of an utterance are intimately related to the process of understanding as such and not to individual verbs. However, more research on this subject will be needed before any definite conclusions can be drawn.

As is evident from the data retrieved from the BNC, grasp mainly appears in nonphysical usages, that is, usages that instantiate a more or less abstract situation. Johnson [1999: 157] suggests that the noun grasp is undergoing changes that make the literal use of the word (I don't have a firm grasp on the handle) seem less natural than the extended metaphorical use (I don't have a firm grasp on the issues). The same kind of change, Johnson states, has resulted in French comprendre 'understand' developing a meaning separate from its Latin root comprehendere 'seize' [1999: 157]. The fact that grasp as a verb predominantly occurs in non-physical extended usages and especially in mental usages could be a sign that both forms of the word - noun as well as verb - are progressively losing connection with their concrete roots. ${ }^{10}$ Semantic changes of this kind usually take a long time to become generally accepted in a linguistic community. Thus, it is more than likely that grasp, both as a verb and as a noun, will continue to be used in concrete as well as in abstract situations in the foreseeable future. As Tuggy puts it: "There is no hard and fast boundary that a form [of a word] needs to jump all at once: it can straddle the fence indefinitely, shifting its weight back and forth, before gradually moving more to one side than the other" [1993: 285]. However, Kemmer and Barlow [2000: x] observe that high frequency of a certain usage results in a higher degree of entrenchment. This means that the more often a word is used in a specific context the more likely it is to be used in the same way again [cf. Allwood 2003: 44]. Therefore, it can be concluded that the fact that grasp, at least as evidenced in the material retrieved from the BNC, is used as a mental verb expressing 'understand' in almost half of the examples is an indication of semantic change. Moreover, it is possible that the high frequency of mental grasp will speed up the process of change even more.

\subsubsection{Graspers}

From the data it is evident that grasp is strongly associated with the use of hands, fingers or arms as well as the brain, as is also shown in Table 1. It follows that the grasper should be human in some way. This is also confirmed by the figures in Table 2 in which the distribution of different graspers is presented: almost $95 \%$ of the data (1,427 instances) can be referred to the group of human graspers.

\footnotetext{
${ }^{10}$ According to the OED, the first written record of the noun grasp dates from 1561, a zero-derivation from the physical verb usage. The first instance of the noun being used within the mental domain is recorded in 1683 , only three years after the first documented appearance of the verb used as 'understand'.
} 


\begin{tabular}{|l|r|r|r|r|}
\hline Type of graspers & \multicolumn{2}{|c|}{ Number of tokens } & \multicolumn{2}{c|}{ Percentage } \\
\hline Human & & 1,427 & & 94.82 \\
\hline $\begin{array}{l}\text { - individual or group } \\
\text { of people }\end{array}$ & 1,285 & & 84.38 & \\
\hline - organisation & 70 & & 4.65 & \\
\hline - body part & 72 & & 4.79 & \\
\hline Non-human (animate) & & 45 & & 2.99 \\
\hline Inanimate & & 6 & & 0.40 \\
\hline Abstract & & 27 & & 1.79 \\
\hline Total & & 1,505 & & 100.00 \\
\hline
\end{tabular}

Table 2. Distribution of graspers

Table 2 clearly shows that the overwhelming majority of graspers are either an individual or a group of people. This group constitutes more than $85 \%$ of the material, or 1,285 instances. The graspers are either explicitly named or referred to with nouns or pronouns, but equally, generic reference is also expressed (anyone, you, etc.). Sentences (35) and (36) are examples of individuals or groups of people as graspers:

(35) I grasped his arm firmly and led him away. [Dibdin, M., Dirty tricks, 1991, FIC]

(36) That is the stark truth electors have to grasp before it is too late. [The Daily Telegraph, electronic edition of 5 April 1992, NEWS]

The grasper need not always be explicitly mentioned but it can be inferred from the context that it is a human. In such cases, the sentence usually receives a generic reading, as exemplified by sentence (37):

(37) Definitions are sometimes hard to grasp on first reading. [Allenby, R.B.J.T., Rings, fields and groups: an introduction to abstract algebra, 1989, AC]

When it comes to organisations viewed as graspers, the material display a very low rate: organisations appear in less than $5 \%$ of the data.

(38) I suspect that Microsoft has been reluctant to grasp the virus nettle [...] [What personal computer: the ultimate guide to choosing and using, 1993, MISC]

(39) But, in general, clubs seem incapable of grasping an elementary fact that cynicism is rife among an ever-increasing number of people who believe that many players are overpaid, overrated and out of touch. [The Liverpool Echo \& Daily Post, 1993, NEWS]

In cases such as these, the grasper is not human per se but is ultimately made up of humans. The organisations function as metonyms for the humans they represent and the ability of human beings to grasp with their hands or with their minds is thus transferred to the organisations.

The fact that body parts often function as metonymic substitutes for humans is a wellknown feature of language (e.g. head of the department, All hands on deck! or We need a pair 
of strong arms here). Depending on what aspect of a person is in focus, different body parts are used metonymically. Kövecses maintains that "[w]hen we are concerned with intellectual abilities, we use the head; when we are interested in certain physical aspects of the person, we use the hand" [2006: 110]. Consequently, it is not surprising that body parts also appear as graspers in some of the data analysed (seventy-two instances or almost 5\%). Since grasp is so strongly associated with the use of one's hands or fingers, it is perhaps more surprising that the examples of body parts as graspers are so few. A possible explanation is provided by Langacker, who states that

we think of the world as being populated by people and objects, not by their parts; and when we do focus on a part, the person or object as a whole is generally invoked as a reference point for its characterization. In this sense the whole has special cognitive salience that makes it a preferred candidate for explicit linguistic coding. [Langacker 1991: 455]

It may also be the case, Langacker continues, that the body part used does not need to be explicitly specified since some verbs activate "a cognitive domain (the conception of a familiar process) that intrinsically specifies the nature of the subject's involvement" [1991: 455]. Sentences (40) and (41) are examples of body parts as graspers:

(40) My eyes began to flicker open as a hand grasped my shoulder. [Howell, B., Dandelion days, 1991, FIC]

(41) [...] as well as forming a compact arrangement quickly grasped by the eye of the conductor. [Jacob, G., Orchestral techniques: a manual for students, 1982, $\mathrm{AC}]$

Apart from example (41), which must be considered an instance of non-physical grasping, most sentences with a body part as the grasper refer to physical grasping, with hand as the predominantly used lexeme (forty-three out of seventy-two instances). Using a body part instead of a human grasper can be seen as an example of the phenomenon active zone as introduced by Langacker: "Those facets of an entity which participate most directly in a relation are referred to as its active zone with respect to that relation" [1991: 454, bold print in original]. In the same fashion, Kövecses argues that the active zone phenomenon is "[a]n interesting special case of the whole thing for part of the thing metonymy" [2006: 100]. When grasp is used as 'understand', the grasper is sometimes described with references made to the human brain:

(42) $[\ldots]$ but her conventional mind could not grasp that a thing so often impure, can be made absolutely and perfectly pure. [Thomas, R.G., Edward Thomas: a portrait, 1987, MISC]

(43) "Facts" do not just exist, they have to be grasped by the intellect, using a conceptual framework. [Bocock, R., Freud and modern society, 1991, AC]

This usage is an example of the body part for the person metonymy: the brain, which is used for understanding, replaces the human as the active part in this particular act of grasping. This is also in line with Kövecses' [2006: 110] statement that the head is often used to describe intellectual abilities. There are only sixteen examples of graspers where reference is made to the brain or the like, but they are nonetheless interesting as illustrations of how physical 
grasping with one's hand has been extended to cover mental grasping with one's brain, with the brain explicitly placed in the role of the grasper.

Close to the typical human grasper are those examples where other primates figure as the grasper. Just like humans, they are able to grasp with their hands. Similarly, the talons of a bird can grasp in much the same way as the hands of humans. Sentences (44) and (45) offer examples with primates and birds respectively:

(44) The larger of the two chimpanzees stood upright and grasped the bars of the cage. [Gallagher, S., Chimera, 1991, FIC]

(45) There, grasping the snail firmly in the talons of one foot, [the Everglades kite] waits. [Attenborough, D., The tricks of life, 1990, MISC]

Examples with other animals often involve the mouth or jaws as the instrument of grasping or the use of some body part in a way similar to that of a human hand. In approximately every sixth or seventh sentence with a non-human grasper, there is an animal body part appearing in the role of the grasper. Just as is the case with gather, this body part can be seen as standing metonymically for the animal as a whole. In total, non-human graspers represent $3 \%$ (fortyfive instances) of the data.

It could be seen as somewhat surprising that both inanimate and abstract entities appear as the grasper. Inanimate entities occur six times in the material analysed and abstract entities as graspers account for another twenty-seven instances. Since neither inanimate nor abstract entities have the ability to grasp anything, either physically or mentally, all these cases exemplify graspers that have been ascribed human qualities. In other words, they have been personified [see, e.g., Lakoff \& Turner 1989: 72-80]. The following examples are illustrations of inanimate entities as graspers:

(46) $[\ldots]$ a huge pain took hold of her left arm, as if an iron claw had grasped it. [Vine, B., King Solomon's carpet, 1992, FIC]

(47) [...] in realist feminist film "what the camera in fact grasps is the "natural" world of dominant ideology". [Women: a cultural review, 1991, MISC]

In example (46), the resemblance between the activity performed by the grasper and that of a human hand is obvious: they are both actions involving taking hold of something and holding it tight, a fact which makes the link to the physical action logical. It is also possible that the use of the lexeme claw may have influenced the choice of verb. In sentence (47), the camera has been assigned the human property of being able to catch something and keep hold of it. Moreover, there is usually a human being behind the camera deciding in what direction to point it. Hence, (47) can be seen as containing an implicit human as the actual grasper with the camera being the instrument used.

Sentences with abstract entities as graspers can be divided into two different groups depending on the interpretation of grasp: extensions from physical grasping and extensions from mental grasping, as shown in sentences (48) and (49) respectively:

(48) They applauded the attempt to cross the sectarian divide to stress the problems common to members of the working-class in both communities. However, they felt that this did not grasp the nettle of community division and conflict [...] [Lovett, T., Radical approaches to adult education: a reader, 1988, $\mathrm{AC}]$ 
(49) The predilection in established forms of leftist media analysis for unravelling hidden agendas has proved incapable of grasping the dynamics of the new situation. [Marxism Today, 1990, MISC]

These examples involve an abstract entity which has been given the human characteristics of being able to deal with a difficult situation and the ability to understand. As is the case for (48) above, it could be argued that the actual grasper in (48) as well as in (49) is human (a group of people) and that the abstract graspers are only metonymic substitutes. Common to both groups with abstract entities as graspers is that the grasper can be quite elaborate and complex.

\subsubsection{Graspees}

There is a small group of examples in the material where grasp seems to be used intransitively, that is, no graspee is explicitly mentioned:

(50) This orang utan demonstrates its ability to grasp efficiently with both hands and feet [...] [Birkhead, M. \& T. Birkhead, The survival factor, 1989, MISC]

(51) [...] every anthropologist has experienced "culture shock"; a temporary inability to grasp and act and think in the terms of the assumptions upon which the newly entered culture is based. [Young, M., An inside job, 1991, AC]

However, there is an implicit graspee conceptually present in these sentences. Whether it be physical or mental grasping, one does not simply grasp, one has to grasp something. In Table 3 , the overall distribution of different graspees is presented. The figures for concrete and abstract graspees correspond well with the proportion of physical usages to non-physical (mental included) usages shown in Table 1.

\begin{tabular}{|l|r|r|r|r|}
\hline Type of graspees & \multicolumn{2}{|c|}{ Number of tokens } & \multicolumn{2}{|c|}{ Percentage } \\
\hline Concrete & & 556 & & 36.94 \\
\hline - concrete entity & 254 & & 16.88 & \\
\hline $\begin{array}{l}\text { - human or human } \\
\text { body part }\end{array}$ & 302 & & 20.06 & \\
\hline Abstract & & & & 62.53 \\
\hline No explicit graspee & & 941 & & 0.53 \\
\hline Total & & 8 & & 100.00 \\
\hline
\end{tabular}

Table 3. Distribution of graspees

In the corpus material there are 556 examples (or approximately $37 \%$ of the data) where the graspee is concrete: 302 instances depict a situation where a human or a human body part functions as the graspee (see (52) below) and in another 254 instances the graspees are concrete entities such as a rope, an iron or a paper, as in (53).

(52) Roberta came running down, grasped Alice, stood rocking the sobbing girl, [...] [Lessing, D., The good terrorist, 1986, FIC] 
(53) The man leans forward, grasps the paper as if to take a closer look at it, [...] [James, R., Payback, 1993, FIC]

Considering that it is often explicitly expressed that the grasping is done with the help of one's hands, a typical graspee should be a concrete entity. Nevertheless, most graspees, 941 examples or $62 \%$ of the material as a whole, belong to the abstract group. Abstract graspees are abstract entities and concepts, often made up by elaborate clauses:

(54) $[\ldots]$ he was a practical man who simply believed power should be grasped and wielded. [Doherty, P.C., Crown in darkness, 1991, FIC]

(55) What he fails to grasp is that if that obstetric experience is withdrawn from Downpatrick, then there will be no selection of patients whatsoever and all will have to make their way to Belfast or Lisburn irrespective of clinical condition. [The Belfast Telegraph, date unknown, NEWS]

Since abstractions are by nature ungraspable, that is, they cannot be physically held with one's hands, in examples such as (54) and (55) grasp is used in a non-physical way. The material on grasp does not contain many high-frequency collocations, the only two are grasp the opportunity (fifty-six tokens; see (3) above) and grasp the nettle (sixty tokens; see (4) above). In addition to the nettle there are other examples where the graspees undoubtedly are concrete entities but used in a non-physical extended way, for example, sentence (56):

(56) When Edward III grasped the reins of government in November 1330, he was as determined as any of his predecessors to vindicate the Forest rights of his Crown. [Grant, R., The royal forests of England, 1991, MISC]

The expression in (56) metaphorically symbolises the king's taking control of government in the same way as a rider or a coachman takes control of the horse(s) by grasping the reins.

So, rather than being explained by a high number of frequent collocations in combination with a fairly high occurrence of mental usages, the fact that most graspees are abstract is mainly the result of the existence of mental grasping (see 2.2.1.3 above), which accounts for almost half of the examples found. Abstractness is a characteristic that all entities processed mentally have in common.

\section{Conclusion}

Generally, as is suggested by the data, grasp can be said to mean (i) 'to take hold of something' and (ii) 'to understand something'. Grasping is usually done with the use of one's hands or the like and in the extended usage of (ii) with one's brain. 'Grasp and hold' is a feature that seems to be common to all the various usages of grasp, which might be an indication that the feature could be seen as central to the semantics of the verb. The extended mental usage of grasp, where the brain is used as the instrument for grasping, is a conceptual mapping common in many languages motivated by metaphors such as IDEAS ARE OBJECTS [Lakoff \& Johnson [1980] 2003] and THE MIND IS A BODY [Sweetser 1990; Lakoff \& Johnson 1999]. Physical grasping, where graspers use their hands, fingers or arms to grasp a (usually) concrete graspee and hold it firmly, accounts for approximately $37 \%$ of the data, whereas non-physical grasping other than mental is represented in a further $15 \%$ of the examples. The 
only two specific collocations with grasp that occur to any greater extent in the data are grasp the opportunity and grasp the nettle.

It is thus mental grasping that has the highest frequency in the material of the three main usage groups. The largest usage within mental grasping is 'understand' and this is also the single most frequent usage of grasp. Besides 'understand', grasp as a mental verb can be interpreted in a number of other ways that are similar in meaning but not exactly the same as understanding. Even though almost all the examples of mental grasping have a human grasper, there are a few with an animal in that role. Since the animals in question are usually regarded as quite intelligent, the data suggests that intelligence might be a prerequisite for grasp to be interpreted as 'understand'.

Typically, graspers are human. This is the case in almost 95\% of the data. Most commonly, human graspers are individuals or groups of people, but there are also examples where body parts function as metonymic substitutes for human graspers.

Considering how grasping is generally carried out, a typical graspee should be a concrete entity of some sort. However, concrete entities only make up just over $42 \%$ of the graspees. Most graspees are instead abstract, either abstract entities/concepts or elaborate clauses. This is explained by the high frequency of mental grasping. In such cases, the graspees cannot, of course, be concrete entities.

To conclude, grasp appears to have a central feature, 'grasp and hold', which is present in all usages, concrete as well as extended. Mental grasping accounts for close to $48 \%$ of the examples. Grasp can thus be said to be readily extended into the mental domain. So much, in fact, that 'understand' is the single largest usage found in the data as a whole. Since, according to the OED, the concrete action predates the mental one with approximately threehundred years, the extension seems to be motivated by similarities perceived between, on the one hand, grasping a physical entity in order to both hold it and examine it and, on the other, grasping a fact in order to understand it. This understanding is achieved by "holding" the fact in one's mind and "examining" it. Given that grasp appears in many various usages in the data, the analysis suggests that the semantic simplicity of the verb might be a factor that facilitates extended usages, especially into the mental domain.

\section{Bibliography}

AllWOOD Jens, "Meaning potentials and context: Some consequences for the analysis of variation in meaning", in CUYCKENS Hubert, DIRVEN René and TAYLOR John R. (Eds.), Cognitive Approaches to Lexical Semantics, Berlin-New York, 'Cognitive Linguistics Research', Mouton de Gruyter, 2003: 29-65.

Alm-Arvius Christina, "Lexical polysemy", in MAGNUSSON Ulf, KARDELA Henryk and GŁAZ Adam (Eds.), Further Insights into Semantics and Lexicography. Lublin, Wydawnictwo Uniwersytetu Marii Curie-Skłodowskiej, 2007: 43-55.

Biber Douglas, Johansson Stig, Leech Geoffrey, Conrad Susan and Finegan Edward, Longman Grammar of Spoken and Written English, Harlow, Longman, 1999.

Evans Vyvyan, The Structure of Time: Language, Meaning, and Temporal Cognition, Amsterdam-Philadelphia, 'Human Cognitive Processing', John Benjamins, 2004.

Fellbaum Christiane, "English verbs as a semantic net", International Journal of Lexicography, Vol. 3.4, 1990: 278-301.

Fillmore Charles J. and ATKINS Beryl T.S., "Describing polysemy: The case of 'crawl'", in RAVIN Yael and LEACOCK Claudia (Eds.), Polysemy: Theoretical and Computational Approaches, Oxford, Oxford University Press, 2000: 91-110. 
GiBBS Raymond W. Jr., The Poetics of Mind: Figurative Thought, Language, and Understanding, Cambridge, Cambridge University Press, 1994.

GibBS Raymond W. Jr. and MATLOCK Teenie, "Psycholinguistic perspectives on polysemy", in CUYCKEns Hubert and Zawada Britta E. (Eds.), Polysemy in Cognitive Linguistics. Selected Papers from the International Cognitive Linguistics Conference, Amsterdam, 1997, Amsterdam-Philadelphia, 'Current Issues in Linguistic Theory', John Benjamins, 1999: 213-239.

Gries Stefan Th. and DivJAK Dagmar, "Behavioral profiles: A corpus-based approach to cognitive semantic analysis", in Evans Vyvyan and Pourcel Stéphanie (Eds.), New Directions in Cognitive Linguistics, Amsterdam-Philadelphia, 'Human Cognitive Processing', John Benjamins, 2009: 57-75.

HANKS Patrick, "Contextual dependency and lexical sets", International Journal of Corpus Linguistics, Vol. 1.1, 1996: 75-98.

IDE Nancy and VÉRONIS Jean, "Introduction to the special issue on word sense disambiguation: The state of the art", Computational Linguistics, Vol. 24.1, 1998: 1-40.

JÄKEL Olaf, "The metaphorical concept of mind: 'Mental activity is manipulation", in TAYLOR John R. and MAClAURY Robert E. (Eds.), Language and the Cognitive Construal of the World, Berlin-New York, 'Trends in Linguistics', Mouton de Gruyter, 1995: 197-229.

JOHNSON Christopher, "Metaphor vs. conflation in the acquisition of polysemy: The case of see", in HIRAGA Masako K., SinHa Chris and WILCOX Sherman (Eds.), Cultural, Psychological and Typological Issues in Cognitive Linguistics. Selected Papers of the Bi-Annual ICLA Meeting in Albuquerque, July 1995, Amsterdam-Philadelphia, 'Current Issues in Linguistic Theory', John Benjamins, 1999: 155-169.

JoHnson Mark, The Body in the Mind: The Bodily Basis of Meaning, Imagination, and Reason, Chicago-London, The University of Chicago Press, 1987.

KeMMER Suzanne and BARLOW Michael, "Introduction: A usage-based conception of language", in BARLOW Michael and KEMMER Suzanne (Eds.), Usage-Based Models of Language, Stanford, CA, CSLI Publications, 2000: vii-xxviii.

KLEIN Devorah E. and MURPHY Gregory L., "The representation of polysemous words", Journal of Memory and Language, Vol. 45.2, 2001: 259-282.

KLEIN Devorah E. and MuRPHY Gregory L., "Paper has been my ruin: Conceptual relations of polysemous senses", Journal of Memory and Language, Vol. 47.4, 2002: 548-570.

KöVECSES Zoltán, Language, Mind, and Culture: A Practical Introduction. Oxford, Oxford University Press, 2006.

LAKOFF George, Women, Fire, and Dangerous Things: What Categories Reveal about the Mind, Chicago-London, The University of Chicago Press, 1987.

LAKOFF George and JoHnson Mark, Philosophy in the Flesh: The Embodied Mind and its Challenge to Western Thought, New York, Basic Books, 1999.

LAKOFF George and Johnson Mark, Metaphors We Live By, Chicago-London, The University of Chicago Press, 2003 [1980].

LAKofF George and Turner Mark, More than Cool Reason: A Field Guide to Poetic Metaphor, Chicago-London, The University of Chicago Press, 1989.

LANGACKER Ronald W., Foundations of Cognitive Grammar, Vol. 1: Theoretical Prerequisites, Stanford, CA, Stanford University Press, 1987.

LANGACKER Ronald W., Foundations of Cognitive Grammar, Vol. 2: Descriptive Application, Stanford, CA, Stanford University Press, 1991.

LDOCE $=$ Longman Dictionary of Contemporary English, $4^{\text {th }}$ ed., Harlow, Longman, 2003.

LEVIN Beth, English Verb Classes and Alternations: A Preliminary Investigation, ChicagoLondon, The University of Chicago Press, 1993. 
MACMILLAN = Macmillan English Dictionary for Advanced Learners, Oxford, Macmillan Education, 2002.

OED $=$ Oxford English Dictionary Online, http://dictionary.oed.com/

PiCKERING Martin J. and Frisson Steven, "Processing ambiguous verbs: Evidence from eye movements", Journal of Experimental Psychology: Learning, Memory, and Cognition, Vol. 27.2, 2001: 556-573.

RoLAND Douglas and JURAFSKy Daniel, "How verb subcategorization frequencies are affected by corpus choice", in ACL/COLING Proceedings 1998, 1998: 1122-1128.

ROLAND Douglas and JURAFSKY Daniel, "Verb sense and verb subcategorization probabilities", in MerLo Paola and Stevenson Suzanne (Eds.), The Lexical Basis of Sentence Processing: Formal, Computational and Experimental Issues, AmsterdamPhiladelphia, 'Natural Language Processing', John Benjamins, 2002: 325-345.

SANDRA Dominiek and RICE Sally, "Network analyses of prepositional meaning: Mirroring whose mind - the linguist's or the language user's?", Cognitive Linguistics, Vol. 6.1, 1995: 89-130.

SinCLAIR John, Corpus, Concordance, Collocation, Oxford, Oxford University Press, 1991.

SweetSer Eve E., Semantic Structure and Semantic Change: A Cognitive Linguistic Study of Modality, Perception, Speech Acts, and Logical Relations, Ph.D. dissertation, University of California, Berkeley, 1984.

SWEETSER Eve E., "Metaphorical models of thought and speech: A comparison of historical directions and metaphorical mappings in the two domains", in Proceedings of the Thirteenth Annual Meeting of the Berkeley Linguistics Society, 1987: 446-459.

SwEETSER Eve E., From Etymology to Pragmatics: Metaphorical and Cultural Aspects of Semantic Structure, Cambridge, 'Cambridge Studies in Linguistics', Cambridge University Press, 1990.

TugGY David, “Ambiguity, polysemy, and vagueness", Cognitive Linguistics, Vol. 4.3, 1993: 273-290.

Tyler Andrea and Evans Vyvyan, The Semantics of English Prepositions: Spatial Scenes, Embodied Meaning and Cognition, Cambridge, Cambridge University Press, 2003.

VANPARYS Johan, "A survey of metalinguistic metaphors", in GoOSSENS Louis, PAUWELS Paul, RudZKA-Ostyn Brygida, SimOn-VANDENBERGEN Anne-Marie and VANPARYS Johan (Eds.), By Word of Mouth: Metaphor, Metonymy and Linguistic Action in a Cognitive Perspective, Amsterdam-Philadelphia, John Benjamins, 1995: 1-34.

VIBERG Åke, "The verbs of perception: A typological study", Linguistics, Vol. 21.1, 1984: 123-162.

WiTtGenSTEIN Ludwig, Philosophical Investigations, Oxford, Blackwell, 1953. 